\title{
Application of cellulose-based polymers in oil well cementing
}

\author{
Ghulam Abbas $^{1}$ (1) $\cdot$ Sonny Irawan ${ }^{2} \cdot$ Khalil Rehman Memon $^{3} \cdot$ Javed Khan $^{4}$
}

Received: 1 November 2018 / Accepted: 4 November 2019 / Published online: 22 November 2019

(c) The Author(s) 2019

\begin{abstract}
Cellulose-based polymers have been successfully used in many areas of petroleum engineering especially in enhanced oil recovery drilling fluid, fracturing and cementing. This paper presents the application of cellulose-based polymer in oil well cementing. These polymers work as multifunctional additive in cement slurry that reduce the quantity of additives and lessen the operational cost of cementing operation. The viscosity of cellulose polymers such as hydroxyethyl cellulose (HEC), carboxymethylcellulose (CMC) and hydroxypropyl methylcellulose (HPMC) has been determined at various temperatures to evaluate the thermal degradation. Moreover, polymers are incorporated in cement slurry to evaluate the properties and affect in cement slurry at $90^{\circ} \mathrm{C}$. The API properties like rheology, free water separation, fluid loss and compressive strength of slurries with and without polymer have been determined at $90{ }^{\circ} \mathrm{C}$. The experimental results showed that the viscosity of HPMC polymer was enhanced at $90^{\circ} \mathrm{C}$ than other cellulose-based polymers. The comparative and experimental analyses showed that the implementation of cellulose-based polymers improves the API properties of cement slurry at $90{ }^{\circ} \mathrm{C}$. The increased viscosity of these polymers showed high rheology that was adjusted by adding dispersant which optimizes the rheology of slurry. Further, improved API properties, i.e., zero free water separation, none sedimentation, less than $50 \mathrm{ml} / 30$ min fluid loss and high compressive strength, were obtained through HEC, CMC and HPMC polymer. It is concluded that cellulose-based polymers are efficient and effective in cement slurry that work as multifunctional additive and improve API properties and cement durability. The cellulose-based polymers work as multifunctional additive that reduces the quantity of other additives in cement slurry and ultimately reduces the operational cost of cementing operation. The comparative analysis of this study opens the window for petroleum industry for proper selection of cellulose-based polymer in designing of cement slurry.
\end{abstract}

Keywords API properties $\cdot$ Cellulose $\cdot$ Cementing $\cdot$ Polymer

$\begin{array}{ll}\text { Abbreviations } \\ \text { API } & \text { American Petroleum Institute } \\ \text { BWOC } & \text { By weight of cement } \\ \text { CMC } & \text { Carboxy methylcellulose } \\ \text { cP } & \text { Centipoise } \\ \text { HEC } & \text { Hydroxyethyl cellulose } \\ \text { HPMC } & \text { Hydroxypropyl methylcellulose } \\ \text { PPG } & \text { Pound per gallon }\end{array}$

Ghulam Abbas

engr_abbas27@live.com; engr_abbas@muetkhp.edu.pk

1 Mehran University of Engineering and Technology, Shaheed Zulfiqar Ali Bhutto Campus, Khairpur Mirs, Pakistan

2 Nazarbayev University, Nur Sultan, Kazakhstan

3 Mehran University of Engineering and Technology, Jamshoro, Pakistan

4 Universiti Teknologi PETRONAS, Seri Iskandar, Malaysia

\section{Introduction}

Polymers are dynamic research area in petroleum industry with respect to their applications. Variety of polymers has been used in different area of petroleum. The polymers are used in enhanced oil recovery, drilling fluid, fracturing application and oil well cementing. Cellulose are natural polymers that can be used as film former, thickener and viscosifying agent in different applications of petroleum industry (Abbas et al. 2013a, b). There are various types of cellulose such as xanthan, guar gum, hydroxypropyl guar, hydroxyethyl group, carboxyethyl and carboxymethyl group (Plank et al. 2009). These all cellulose-type polymers are used in different fields. Besides other applications, it has excellent usage in oil well cementing operations (Roshan and Asef 2010). Cement is the key material that has been used during drilling operation to provide zonal isolation, protect the casing string and provide the strength for installing wellhead (Pour and Moghadasi 2007). The oil well cement is mixed 
with water and other additives like dispersant, accelerator, deformer, retarder, fluid loss additive and loss circulation materials for their specific properties in cement slurry (Bayer and Knarr 2012). But in oil well cementing, the used additives have limitations related to temperature, pressure and admixture property with other additives and cement. The usages of multiple additives in cement slurry encourage the compatibility issue with cement material that reduces the efficiency of cement durability (Abbas et al. 2013a, b). This improper cement slurry creates the crakes and voids in cement. With the passage of time, it becomes permeable zone and the fluid lost from cement slurry. This fluid loss created permanent channel that becomes the cause of fluid migration to surface as shown in Fig. 1. On the other hand, the usages of multiple additives in designing of cement slurry increase the economical cost of cementing operation (Reddy and Patil 2012).

Oil industry moves to polymer that has more advantages on numerous additives. There are number of polymers that have been used in petroleum industry. From all of them, cellulose-based polymer has variety of applications in oil well cementing where it acts as multipurpose and functional additive in oil well cement slurry at wide range of density and temperature (Brandl et al. 2012). The single derivative of cellulose polymer has advantage on other polymers as being film former and viscosifying agent that could be used in cement slurry for gas migration and fluid lose control (Reddy and Patil 2012). Therefore, this paper presents the applications of cellulose type polymers in cement slurry to evaluate their effect on cement slurry. The polymers like guar gum, xanthan and hydroxypropyl guar were studied by various authors to evaluate their effect in cement slurry at different temperature ranges. There was gap in the literature for comparative analysis of natural cellulose polymer and their applications in cementing operations. Therefore, the
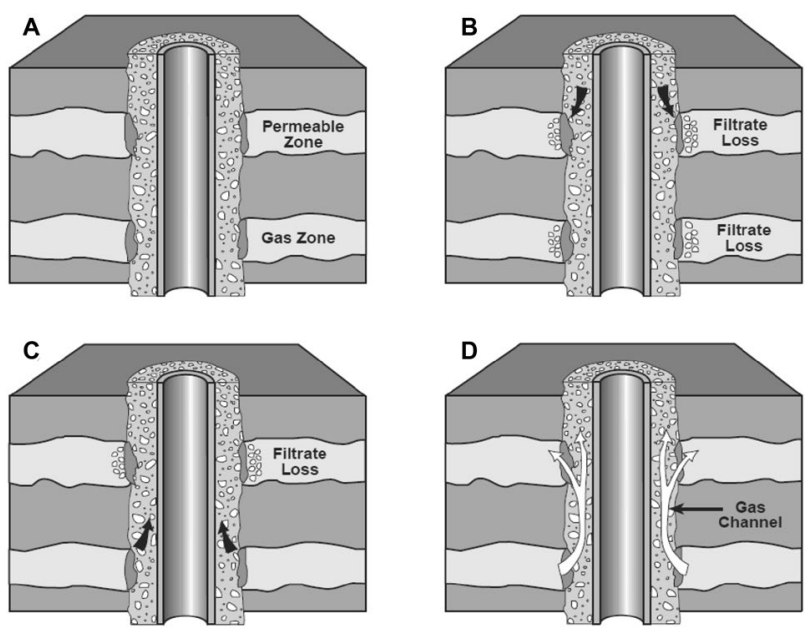

Fig. 1 Gas migration problem due to improper cement selection comparative study on the base of experiments for cement slurry design has been studied for the first time in this paper using different derivatives of cellulose. The comparative analysis through viscosity and API properties of cement slurries of this study assists the petroleum industry for proper selection of cellulose polymer for cementing operation. The present study is limited to viscosity determination of cellulose polymers at $90^{\circ} \mathrm{C}$ and API properties measurement in term of rheology, fluid loss, sedimentation, free water separation and compressive strength of cement slurries.

The derivatives of cellulose ethyl, methyl and propyl methyl group like HEC, CMC and HPMC have been investigated. As cellulose polymers have been considered as viscosifier, the comparative analysis of viscosity using HEC, $\mathrm{CMC}$ and HPMC, respectively, has been performed at $90^{\circ} \mathrm{C}$ with respect to shear rates through experiment using HPHT viscometer. In next, this study explores the prospective of cellulose-based polymer in oil well cementing at elevated temperature of $90^{\circ} \mathrm{C}$. The slurry of $15.8 \mathrm{lb}$ per gallon (ppg) density having class $\mathrm{G}$ cement system was prepared and used to study the effect of cellulose-based polymer on API properties of cement slurries. The different experiments have been performed using various cement slurries in order to determine API properties such as free water, sedimentation of particles, fluid loss, rheology as well as compressive strength with and without addition of HEC, CMC and HPMC.

\section{Materials and methods}

The experimental plan for this study was accomplished by using API-recommended practice. The API RP 10B-2 provides the recommended practice for designing of cement slurries, preparation and testing the specified API properties of cement slurries (API Practice 2009). The class G cement having specific gravity of 3.14 was used for preparation of slurries with other additives such as deformer, fluid loss additive, dispersant and cellulose-based polymer. The class $\mathrm{G}$ cement contains different concentrations of various components such as $\mathrm{SiO}_{2}, \mathrm{AL}_{2} \mathrm{O}_{3}, \mathrm{Fe}_{2} \mathrm{O}_{3}, \mathrm{TIO}_{2}, \mathrm{~K}_{2} \mathrm{O}, \mathrm{P}_{2} \mathrm{O}_{5}$, $\mathrm{CaO}, \mathrm{MgO}, \mathrm{SO}_{3}$ (Ou et al. 2012).

\section{Preparation of polymer solution and viscosity measurement method}

It was necessary for viscosity measurement that the polymers should be in liquid form. Therefore, the liquid solution of polymers was prepared using distilled water by performing the experiment through hot magnetic plate at room temperature (Abbas et al. 2015). The $02 \mathrm{wt} \%$ concentration of each polymer solution was prepared for investigation.

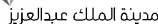

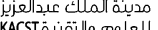
Springer 
The viscosity of HEC, CMC and HPMC polymer solutions was determined through HPHT viscometer at $90{ }^{\circ} \mathrm{C}$ and $1-1000 \mathrm{~S}^{-1}$ shear rates.

\section{Preparation of cement slurries method}

The series of slurries were prepared using polymer and additives with class $\mathrm{G}$ cement for API properties of cement slurry measurement. The cement slurries were prepared through speed mixture equipment where fluctuating dosage of additives mixed with class $\mathrm{G}$ cement having concentration of 100 BWOC (by weight of cement) and water in all cement slurries. Different concentrations of additives such as naphthalene sulfonate (dispersant), silicone (defoamer), borates (retarder), sodium polyacrylate (fluid loss) have been mixed with cellulose to prepare cement slurries. The cement slurry formulation is given in Table 1.

\section{API properties of cement slurries measurement methods}

The API properties of prepared cement slurries will be determined at elevated temperature of $90{ }^{\circ} \mathrm{C}$. Therefore, it was necessary to increase the temperature of cement slurry manually. In order to enhance the temperature, the formulated cement slurries were preheated and conditioned in atmospheric consistometer at $90{ }^{\circ} \mathrm{C}$ for $20 \mathrm{~min}$ to elevate the temperature of slurries in order to perform API properties measurement experiments.

In next for determination of rheology in term of plastic viscosity and yield point of cement slurries, the rotation viscometer has been used. The preheated cement slurry was transferred in rotational viscometer to determine rheology of slurries.

In next, the preheated cement slurries were poured in graduated cylinder and kept at $45^{\circ}$ angle to observe the effect of cement particles sedimentation and separation of free water (Ganguli 1993).

The loss of fluid through cement slurries of preheated slurries was determined using HPHT filter press having
$175 \mathrm{ml}$ cell with $45 \mu \mathrm{m}$ (325) mesh screen of OFIT company at $90{ }^{\circ} \mathrm{C}$ temperature and 1500 psi pressure (Baig et al. 2017).

To simulate the effect of cellulose-based cement slurries on compressive strength for bottom hole condition, the compressive strength of cement slurries was determined through ultra sonic cement analyzer for the time period of $18 \mathrm{~h}$ (Xuli and Chung 1996). The temperature for complete experiment was $90{ }^{\circ} \mathrm{C}$, and the pressure was $3000 \mathrm{psi}$.

\section{Results and discussion}

\section{Viscosity of cellulose-based polymer}

The viscosity of 02 weight percent solution of HEC, CMC and HPMC polymer was determined at $90{ }^{\circ} \mathrm{C}$ at different shear rates as shown in Fig. 2. Initially at $1 \mathrm{~S}^{-1}$ shear rate, the viscosity of these polymers was high, but the viscosity was reduced as shear rate was increased. The measured viscosity of HEC solution was 7 centipoise (cP), the viscosity of CMC solution was $25 \mathrm{cP}$, and the viscosity of

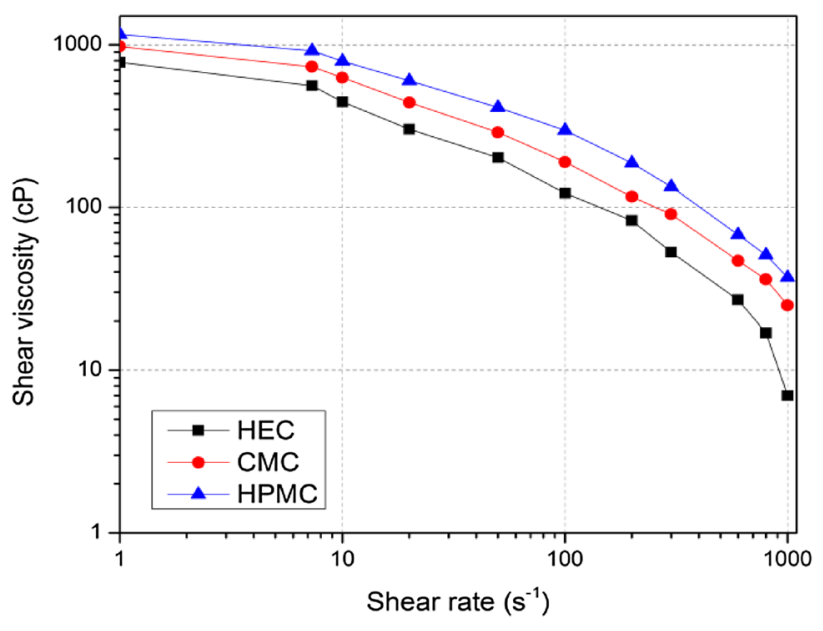

Fig. 2 Viscosity of cellulose-based solutions at $90{ }^{\circ} \mathrm{C}$
Table 1 Designing of cement slurries

\begin{tabular}{|c|c|c|c|c|c|c|c|}
\hline \multirow[t]{2}{*}{ Slurry no. } & Dispersant & $\begin{array}{l}\text { Fluid loss } \\
\text { additive }\end{array}$ & Defoamer & Retarder & HEC & $\mathrm{CMC}$ & HPMC \\
\hline & gps & gps & gps & gps & gps & gps & gps \\
\hline 01 & 0.20 & 0.30 & 0.02 & 0.04 & - & - & - \\
\hline 02 & - & - & 0.02 & 0.04 & 0.30 & - & - \\
\hline 03 & 0.20 & 0.30 & 0.02 & 0.04 & 0.30 & - & - \\
\hline 04 & - & - & 0.02 & 0.04 & - & 0.30 & - \\
\hline 05 & 0.20 & 0.30 & 0.02 & 0.04 & - & 0.30 & - \\
\hline 06 & - & - & 0.02 & 0.04 & - & - & 0.30 \\
\hline 07 & 0.20 & 0.30 & 0.02 & 0.04 & - & - & 0.30 \\
\hline
\end{tabular}


HPMC solution was $36 \mathrm{cP}$ at $1000 \mathrm{~S}^{-1}$. The HEC polymer solution showed very low viscosity than other solutions. It shows that at $90{ }^{\circ} \mathrm{C}$ with high shear rate, the HEC polymer degrades and showed minimum viscosity. On the other hand, HPMC polymer shows high viscosity and could act as viscosifying agent at $90{ }^{\circ} \mathrm{C}$ with respect to other polymers.

\section{Properties of cellulose-based cement slurries}

The cement slurries of $15.8 \mathrm{ppg}$ density were prepared to observe the effect of cellulose-based polymers at $90{ }^{\circ} \mathrm{C}$. A series of cement slurries of altered dosage of additives and polymers were prepared as formulation is shown in Table 1. The properties of all slurries are shown in Table 2 and discussed separately.

\section{Rheology of cement slurries}

The plastic viscosity and yield point are considered important rheological properties of cement slurries to control pressure drop and creating turbulent flow for mud cake removal (Sarkar and Walker 1995). It was observed that cellulose-based slurries-2 to 7 show increased plastic viscosity and yield point as shown in Table 2 . As the cellulose is a long-chain polymer, it increases the viscosity in cement slurries that absorbs water on cellulose group. As HPMC and CMC showed less temperature and shear rate degradation than HEC solution, in cement slurries the plastic viscosity and yield point of these both solutions were higher than that of HEC-based slurries. On the other hand, the enhanced viscosity affects the pressure drop. Therefore, it will increase the pressure drop and create problems during displacement of slurry. The friction reducing agent like lignosulfonate called dispersant was added in slurries to adjust the viscosity and enhance the rheology of slurries. The addition of 0.20 gps of dispersant adjusts the plastic viscosity and yield point of cellulosebased cement slurries.

\section{Sedimentation and free water}

The sedimentation of designed cement slurries was analyzed through visual observation in graduated cylinder through API slandered (Ganguli 1993). As discussed in materials and methods section, the cement slurry was poured in the graduate cylinder that was kept at $45^{\circ}$ angle according to API slandered to observe the effect of sedimentation (API API Practice 2009). The determination of sedimentation is based on only visual observation of sediment particles in cement slurry. The slurry-01 that was without cellulose polymer showed heavy sediments and $12 \mathrm{ml}$ free water was collected from the top of slurry that was poured in graduated cylinder. The slurry that has heavy sediments creates non-homogeneity in cement which directly affects the compressive strength of slurry. The sediment and free water separation can be reduced by adding any viscosifying agent. Therefore, the free water separation and sedimentation was reduced by adding cellulose polymer in cement slurries as observed in slurries 02-07 and shown in Table 2. It was observed that slurries-06 and 07 have no sedimentation and the free water separation was less than $05 \mathrm{ml}$. It was due to the viscosity of cement slurry as these both slurries contain HPMC that have high viscosity than that of other both polymer solutions. Therefore, HPMC polymer is considered as better viscosifying agent than other cellulose polymer for controlling free water separation and particle sedimentation.

\section{Fluid loss of cement slurries}

Under the pressurized condition of wellbore, the loss of fluid creates channel in the cement sheath. During settling time of cement, it becomes permanent and gas starts to migrate through these channels that ultimately disturb the complete phenomena of drilling operation. According to API standard, the fluid loss through cement slurries should be less than $50 \mathrm{ml}$ in $30 \mathrm{~min}$ and it could be achieved by adding
Table 2 API properties of cement slurries at $90{ }^{\circ} \mathrm{C}$

\begin{tabular}{lllllll}
\hline Slurry no. & $\begin{array}{l}\text { Plastic viscos- } \\
\text { ity (PV) cP }\end{array}$ & $\begin{array}{l}\text { Yield } \\
\text { point (YP) } \\
\mathrm{Ib} / 100 \mathrm{ft}^{2}\end{array}$ & Free water ml & Sedimentation & $\begin{array}{l}\text { Fluid loss } \\
(\mathrm{ml} / 30 \mathrm{~min})\end{array}$ & $\begin{array}{l}\text { Compressive } \\
\text { strength (Psi) }\end{array}$ \\
\hline 01 & 48 & 30 & 12 & Heavy & 65 & 2430 \\
02 & 72 & 47 & 10 & Medium & 42 & - \\
03 & 59 & 35 & 08 & Medium & 29 & 2700 \\
04 & 78 & 51 & 07 & Medium & 33 & - \\
05 & 64 & 42 & 04 & None & 18 & 3700 \\
06 & 85 & 58 & 03 & None & 25 & - \\
07 & 71 & 49 & 01 & None & 15 & 3600 \\
\hline
\end{tabular}




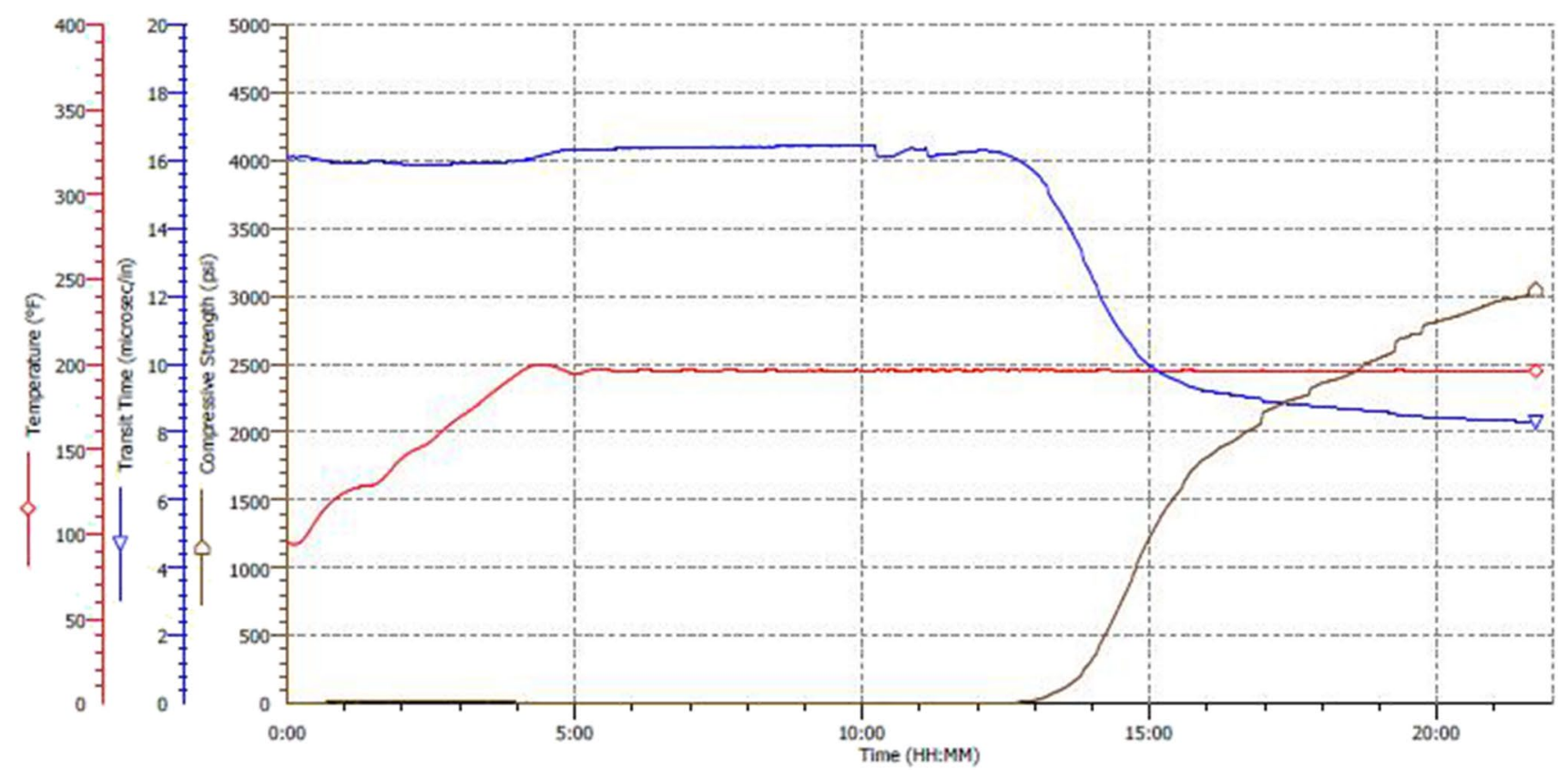

Fig. 3 Compressive strength of slurry-01(without polymer)

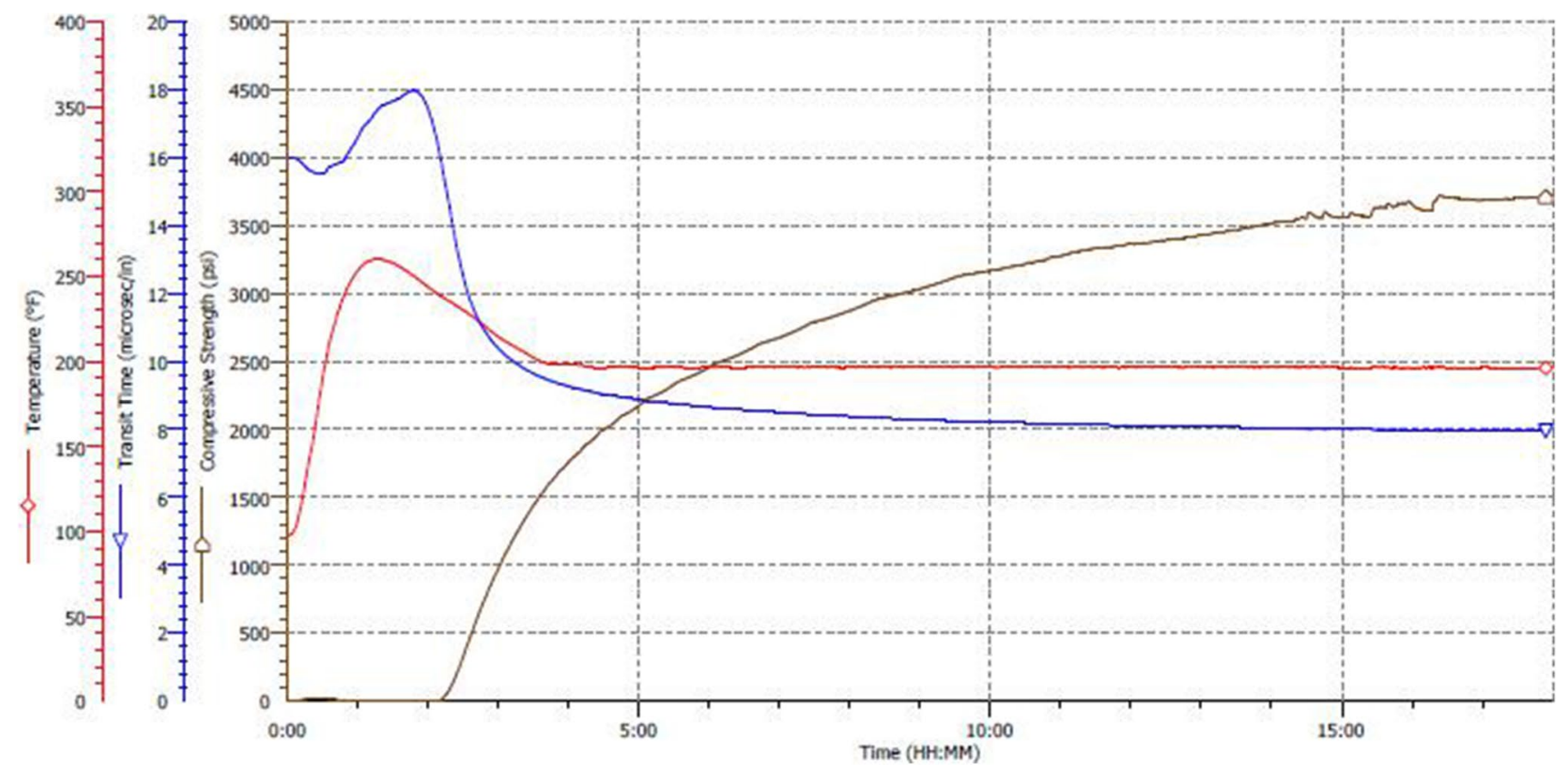

Fig. 4 Compressive strength of slurry-05 (CMC polymer)

viscosifying agent (Ganguli 1991). Through the laboratory experiment of HPHT filter press it was observed that the addition of cellulose polymer like HEC, CMC and HPMC in cement slurry reduces the fluid loss. Secondly, it depends upon the viscosity of polymer solution at elevated temperature. It was observed that the fluid loss of slurry-01 without polymer solution was higher than that of other slurries- 02 to 07 which comprise cellulose polymer. The reduced fluid loss was due to the impact of addition of these polymers in cement slurry, as these polymers act as film former and thicker at specified temperature that enhances the viscosity and reduce the removal of water at high temperature. 


\section{Compressive strength of slurries}

The compressive strength of slurries is considered an important characteristic of drilling cement as it is related to tensile strength and elastic property of slurry. The high compressive strength increases the service life of well, provides the zonal isolation and supports the wellhead at surface (Sabins and Sutton 1986). Therefore, the compressive strength of improved cement slurries with other additives is determined and discussed in this paper. It was observed that the polymer-based cement slurries 03, 05 and 07 showed improved compressive strength than slurry-01 as shown in Figs. 3 and 4. The addition of cellulose polymer in cement increases the compressive strength and gains the early compressive strength as shown in Figs. 3 and 4. In compressive strength analysis, the $3 \mathrm{D}$ structure chain of cellulose creates the strong chemical bond with other components and it increases the compressive strength between the cement particles.

\section{Conclusions}

The API properties of $15.8 \mathrm{ppg}$ density cement slurries were determined to observe the effect of cellulose polymers on cementing operation. Through the experimental study, it was concluded that:

- The viscosity of HPMC polymer was greater than CMC and HEC polymer solutions at $90{ }^{\circ} \mathrm{C}$. This showed that at high temperature the HPMC will be more stable and will behave as viscosifying agent in cement slurry than other cellulose polymers.

- It is necessary to use friction reducing agents like dispersant in polymer-based cement slurries in order to improve the rheology such as plastic viscosity and yield point for reducing pump pressure during displacement.

- The cellulose-based polymer has been used as multipurpose and multifunctional additive in cement slurry, as single integer of cellulose reduces the loss of fluid, sedimentation of particles and free water separation through cement slurries at high temperature.

- The cellulose-based polymers also enhance the early compressive strength of cement slurries. The HPMC solution showed high compressive strength than that of other cellulose-based polymer.

\section{Recommendations}

The present study is limited to performance evaluation of cellulose derivatives in cement slurries. Further studies should be carried out for determination of transient time period as well gas migration through cement slurries. It is also recommended to evaluate the performance of these derivatives in other filed of petroleum related to enhanced oil recovery, fracturing and drilling fluid through comparative analysis.

Acknowledgements The authors would like to thanks Mehran UET, S.Z.A.B Campus to publish this research work. The authors also would like to thank Universiti Teknologi PETRONAS and Baker Hughes, Malaysia, for conducting the experimental work at laboratory.

Open Access This article is distributed under the terms of the Creative Commons Attribution 4.0 International License (http://creativeco mmons.org/licenses/by/4.0/), which permits unrestricted use, distribution, and reproduction in any medium, provided you give appropriate credit to the original author(s) and the source, provide a link to the Creative Commons license, and indicate if changes were made.

\section{References}

Abbas G, Irawan S, Kumar S, Elrayah A (2013a) Improving oil well cement slurry performance using hydroxypropylmethylcellulose polymer. Adv Mater Res 787:222-227

Abbas S, Donovan J, Sanders A (2013b) Applicability of hydroxyethylcellulose polymers for chemical EOR. In: The SPE enhanced oil recovery conference, Kuala Lumpur, SPE 165311 MS

Abbas G, Irawan S, Memon MK, Kalwar SA, Kumar S (2015) Hydroxypropylmethylcellulose as a free water and settling control agent in oil well cement slurry. Springer, Singapore, pp 121-128

API (2009) Recommended practice for testing well cements. API, 10B2, Washington

Baig MT, Rehman MK, Al Majid A (2017) Application of nanotechnology in oil well cementing. In: The SPE Kuwait oil and gas show and conference, Kuwait, SPE 187543-MS

Bayer R, Knarr M (2012) Thermal precipitation or gelling behavior of dissolved methylcellulose (MC) derivatives-behaviour in water and influence on the extrusion of ceramic pastes. Part 1: fundamentals of MC-derivatives. J Eur Ceram Soc 32(5):1007-1018

Brandl A, Bray, C Magelky (2012) Improving well cementing quality with an environmentally preferred multifunctional polymer. In: The SPE Europec/EAGE annual conference, Denmark, SPE 154498-MS

Ganguli K (1991) A cost effective fluid loss/gas control cement slurry design. Chemical Technology Development, The Western Company, The Woodlands, SPE 22533

Ganguli K (1993) Biopolymers as free water and settling control agent. In: The SPE production operations symposium, Oklahoma, SPE25437 MS

Ou Z, Ma B, Jian S (2012) Influence of cellulose ethers molecular parameters on hydration kinetics of Portland cement at early ages. Constr Build Mater 33:78-83

Plank J, Dugonjic-Bilic F, Lummer NR (2009) Comparative study of the working mechanisms of chemically different cement fluid loss polymers. In: The SPE international symposium on oilfield chemistry, The Woodlands, SPE 121542 MS

Pour MM, Moghadasi J (2007) New cement formulation that solves gas migration problems in Iranian south pars field condition. In: The 15th SPE Middle East oil and gas show and conference, Bahrain, SPE 105663MS 
Reddy BR, Patil R, Patil S (2012) Chemical modification of biopolymers to design cement slurries with temperature-activated viscosification-a laboratory study. SPE Drill Complet 27(2):94-102

Roshan H, Asef M (2010) Characteristics of oilwell cement slurry using CMC. SPE Drill Complet 25(3):328-335

Sabins F, Sutton D (1986) The relationship of thickening time, gel strength, and compressive strength of oil well cements. SPE Prod Eng 1-2:143-152

Sarkar N, Walker L (1995) Hydration dehydration properties of methylcellulose and hydroxypropylmethylcellulose. Carbohydr Polym 8617-95:177-185
Xuli F, Chung D (1996) Effect of methylcellulose admixture on the mechanical properties of cement. Cem Concr Res 26-4:535-538

Publisher's Note Springer Nature remains neutral with regard to jurisdictional claims in published maps and institutional affiliations. 